\title{
Assessment of various Peach rootstocks for germination and seedling growth
}

\author{
Javed Rahman*, Muhammad Abdur Rauf, Khalil ur Rahman, \\ Muhammad Ibrahim, Farooq, Noor Habib Khan and Muhammad Junaid \\ Agricultural Research Institute, Mingora Swat, KPK, Pakistan \\ *Corresponding author's email: javedmiandam@gmail.com \\ Citation \\ Javed Rahman, Muhammad Abdur Rauf, Khalil ur Rahman, Muhammad Ibrahim, Farooq, Noor Habib Khan and \\ Muhammad Junaid. Assessment of various Peach rootstocks for germination and seedling growth. Pure and Applied \\ Biology. Vol. 5, Issue 2, 2016, pp200-203. http://dx.doi.org/10.19045/bspab.2016.50026

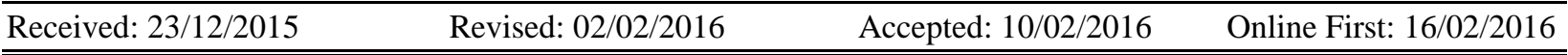

\section{Abstract}

Peach root stocks "Swat local", "Chitral local" and "Okinawa" were evaluated to assess their performance in nursery at Agricultural Research Institute Mingora, Swat Pakistan during 201314. Days to germination, percent seed germination, seedling diameter, number of branches per seedling, number of leaves per seedlings and seedling height were found significant in all the three rootstocks. The indigenous root stock "Swat local" and "Chitral local" performed well for the aforementioned traits. The rootstock "Okinawa" had earlier germination.

Key words: Peach; Rootstocks; Nursery; Germination; Seedling growth

\section{Introduction}

Peach (Prunus persica L.) is an important temperate fruit of Pakistan especially of Khyber Pakhtunkhwa province. Climate of the province is suitable for peach production. Peach requires 200-1000 chilling hours to break bud dormancy [1]. Hot and arid zones are best suited for quality fruit production than the humid areas as disease susceptibility is higher to brown rot and leaf curl. The prerequisite for better fruit production is absence of late spring frost and presence of bright sun [2]. Weather extreme in both cases, either very hot or very cold, adversely affects the fruit production. Lower temperature causes winter injury including bud injury, twig killing, collar injury and bark splitting [3].

The rootstock plays a vital role in the overall growth, development and fruiting of the plant. The farmers must have best knowledge of both the scion and rootstocks as the selection of root stock is vital when fruit plants are grown on soil having high bulk density, parasite problems, drought and water logging issues [4].

The peach root stocks are propagated through seed around the world, although the seeds of different rootstock having variation in their chilling requirements to germinate [5]. In Pakistan mostly "Swat local" (wild peach) is used as a root stock for peach. Both the nurserymen and growers facing problems in seed germination and uniformity of seedlings for budding. Therefore the present research was designed to study the germination and seedling growth of different peach root stocks.

\section{Materials and methods}

Three Peach rootstocks viz; Swat Local, Chitral local and Okinawa were evaluated at Agriculture Research Institute Mingora Swat 
during 2013-14. The trial was laid out in Randomized Complete Block Design (RCBD) in three replicates. Seeds were sown in plastic tubes containing silt, sand and farm yard manure at 1:1:1 ratio, respectively. There were 50 seed in one replication of each rootstock and one seed per plastic tubes. Seeds were irrigated soon after sowing with fountain. Same cultural practices (irrigation, weeding and fertilization) were carried out in all the treatments. The data were recorded on the days to $50 \%$ germination, Percent germination, Seedling diameter $(\mathrm{mm})$, number of branches seedling ${ }^{-1}$, and number of leaves seedling ${ }^{-1}$ and Seedling height (cm).

\section{Statistical analysis}

The data obtained was statistically analyzed as per procedure appropriate for RCB design using statistical package, Statistix 8.1. Upon significance least significance difference (LSD) test was performed for mean comparison.

\section{Results and discussion}

\section{Days to 50\% germination}

The data on $50 \%$ germination is presented in Table 1. Analysis of data showed that different rootstocks had significant influence on days to $50 \%$ germination. Peach rootstock Swat local and Chitral local took more days for $50 \%$ germination, respectively while seeds of Okinawa germinate earlier. The chilling requirements affects the germination in Peach rootstocks thus Okinawa is low chill rootstock and germinate earlier $[5,6]$.

\section{Germination percentage}

Table 1 depicts the mean data of germination percentage that was significantly different for all the peach rootstocks at $5 \%$ probability level. Chitral local had higher germination percentage than Okinawa and Swat local. The probable reason for improved germination on Chitral local rootstock might be due to the well filled, large and good quality kernel as compared to other two rootstocks. The results are in conformation with the findings of $[7,8]$ who also reported higher germination percentage for the rootstock that had larger and good quality seed.

\section{Seedling diameter (mm)}

Seedling diameter was significantly different for all three peach rootstocks (Table 1). Seedling diameter was higher in Chitral local closely followed by Swat local and was minimum in peach rootstock Okinawa. The Okinawa root stock is exotic and not adoptable to the environment of Pakistan thus the seedlings are of thinner diameter. According to [5] the growth of seedlings is affected by adoptability to the new environment.

Table 1. Days to $50 \%$ germination, Germination percentage and Seedling diameter of peach rootstocks

\begin{tabular}{|l|l|l|l|}
\hline Root Stock & $\begin{array}{l}\text { Days to } \\
\text { germination }\end{array}$ & G0\%mination (\%) & $\begin{array}{l}\text { Seedling diameter } \\
(\mathbf{m m})\end{array}$ \\
\hline Swat local & $143.33 \mathrm{a}$ & $72.66 \mathrm{~b}$ & $6.57 \mathrm{~b}$ \\
\hline Chitral Local & $141.00 \mathrm{a}$ & $80.66 \mathrm{a}$ & $6.86 \mathrm{a}$ \\
\hline Okinawa & $126.00 \mathrm{~b}$ & $62.66 \mathrm{c}$ & $6.10 \mathrm{c}$ \\
\hline LSD $_{0.05}$ & 3.64 & 5.90 & 0.11 \\
\hline
\end{tabular}

\section{Seedling height $(\mathrm{cm})$}

The data regarding seedling height are given in Table 2. Seedling diameter was significantly affected by different peach root stocks. Mean values of the data indicated that tallest seedling was noted in swat local root stock followed by Chitral local whereas Okinawa had dwarf seedlings. The growth habit of swat local is erect thus produce 
tallest seedlings while the Chitral local having spreading type growth and Okinawa is exotic rootstock and not well adopted to the environmental condition thus produce smallest plants. The present results are in accordance with [5, 9] who also reported that the rootstocks which are not well adopted to environment had produced smallest plants.

\section{Number of branches seedling ${ }^{-1}$}

The mean data of number of branches seedling $^{-1}$ is presented in Table 2 . Significant differences were observed among Peach genotypes for number of branches seedling ${ }^{-1}$. The count of branches seedling $^{-1}$ was maximum in peach rootstock Chitral local; While Swat local and Okinawa were far behind in number of branches seedling $^{-1}$ than Chitral local. The maximum number of branches is due to the fact that the plants of Chitral local peach is spreading in nature and hence produce maximum branches seedling ${ }^{-1}$. Significant differences among the growth of different rootstock seedlings and less number of branches in erect type growth habit rootstocks was also reported by [10].

Number of leaves seedling ${ }^{-1}$

Analysis of variance showed significant disparity among all three peach rootstocks for number of leaves seedling ${ }^{-1}$ (Table 2). Chitral local produced more leaves seedling 1 , followed by Swat local whereas, Okinawa produced less number of leaves seedling ${ }^{-1}$. The maximum number of leaves seedling ${ }^{-1}$ is might be due to the maximum number of branches seedling ${ }^{-1}$ and vice versa. The results are in close consideration with the findings of [11] they reported significant differences among different root stock.

Table 2. Seedling diameter, Number of branches seedling and Seedling diameter of peach rootstocks

\begin{tabular}{|l|l|l|l|}
\hline Root Stock & $\begin{array}{l}\text { Seedling height } \\
(\mathbf{c m})\end{array}$ & Branches seedling $^{-1}$ & $\begin{array}{l}\text { Leaves seedling } \\
\mathbf{1}\end{array}$ \\
\hline Swat local & $123.85 \mathrm{a}$ & $9.00 \mathrm{~b}$ & $273.4 \mathrm{~b}$ \\
\hline Chitral Local & $113.33 \mathrm{~b}$ & $18.14 \mathrm{a}$ & $422.3 \mathrm{a}$ \\
\hline Okinawa & $98.41 \mathrm{c}$ & $5.567 \mathrm{c}$ & $204.7 \mathrm{c}$ \\
\hline LSD $_{0.05}$ & 3.70 & 1.49 & 3.4 \\
\hline
\end{tabular}

\section{Conclusions and recommendation}

It is concluded that Peach rootstock "Chitral local" had higher germination percentage, seedling diameter, branches seedling ${ }^{-1}$ and number of leaves seedling ${ }^{-1}$ whereas Swat Local had erect growth habit and attained maximum seedling height. Hence Chiral local and Swat Local were recommended for North West regions of Pakistan. Further research is also suggested for compatibility and yield with scion cultivars.

Authors' contributions

Conceived and designed the experiments: J Rahman, MA Rauf \& K Rahman, Performed the experiments: J Rahman, Farooq \& M Ibrahim, Analyzed the data: J Rahman \&
NH Khan, Contributed reagents/ materials/ analysis tools: J Rahman \& N Junaid, Wrote the paper: MH Khan \& M Junaid.

\section{References}

1. Gunes NT (2006). Frost hardiness of some Turkish apricot cultivars during the bloom period. Hort Science 41(2): 310312.

2. Rodrigo J (2000). Spring frost in deciduous fruits morphological damage and flower hardiness. Scientia Hort 85: $155-173$.

3. Westwood MN (1993). Temperate zone pomology. Physiology and culture. Timber press, Portland, Ore. 
4. Headley (2006). The effect of root stocks on growth and yield. $J$ Hort Science and Biotech 81(6): 1064-1068.

5. Hortman HT, Kester DE, Davies FT \& Geneve RL (2011). Plant propagation: principles and practices, 8th ed. Upper Saddle River: Prentice Hall.

6. Rehman N, Hussain I, Nisa Z \& Awan AA (1999). Germination study on five different varieties of pecan nuts. Pakistan J Biol Science 2(3): 917-918.

7. Baskin CC \& Baskin JM (1998). Seeds: Ecology, Biogeography, and Evolution of Dormancy and Germination. Academic Press, New York.

8. Malcolm PJ, Holfold P, Mcglasson WB \& Newman S (2003). Temperature and seed weight affect the germination of peach rootstock seeds and the growth of rootstock seedlings. Scientia Horticulturae 98: 247-256.

9. Layne REC \& PY Jui (1994). Genetically diverse peach seedlings rootstock affect long term performance of "Redhaven" peach. J American Soc Hort Science 119: 1303-1331.

10. Taha NM \& Mohamed AT (2011). Morphological and anatomical evaluation of new five root stocks. $J$ American Science 7(3): 135-152.

11. Wongtanet D \& Bronprakob U (2010). Effect of rootstock on growth of peaches in the highland of Northren Thailand. Acta Hortic 872: 327-332. 